\title{
Switching sliding mode force tracking control of piezoelectric-hydraulic pump-based friction element actuation systems for automotive transmissions
}

\author{
Gi-Woo Kim and K W Wang \\ Department of Mechanical Engineering, University of Michigan, Ann Arbor, MI 48109, USA \\ E-mail: gwkim@umich.edu
}

Received 19 January 2009, in final form 23 January 2009

Published 3 June 2009

Online at stacks.iop.org/SMS/18/085004

\begin{abstract}
In this study, a nonlinear sliding-mode controller is designed for force tracking of a piezoelectric-hydraulic pump (PHP)-based actuation system, which is developed to replace the current electro-hydraulic actuation systems for automatic transmission (AT) friction elements, such as band brakes or clutches. By utilizing the PHP, one can eliminate the various hydraulic components (oil pump, regulating valve and control valve) in current ATs and achieve a simpler configuration with more efficient operation. With the derived governing equation of motion of the PHP-based actuation system integrated with the friction element (band brake), a switching control law is synthesized based on the sliding-mode theory. To evaluate the effectiveness of the proposed control law, its force tracking performance for the engagement of a friction element during an AT $1 \rightarrow 2$ up-shift is examined experimentally. It is shown that one can successfully track the desired force trajectory for AT shift control with small tracking error. This study demonstrates the potential of the PHP as a new controllable actuation system for AT friction elements.
\end{abstract}

(Some figures in this article are in colour only in the electronic version)

\section{Nomenclature}

$A_{1} \quad$ Ram (effective) area of head side in double-acting hydraulic cylinder $\left(\mathrm{m}^{2}\right)$

$A_{2} \quad$ Ram area (effective) area of rod side in double-acting hydraulic cylinder $\left(\mathrm{m}^{2}\right)$

$A_{\mathrm{p}} \quad$ Diaphragm area $\left(\mathrm{m}^{2}\right)$

$A_{\mathrm{o}} \quad$ Orifice area $\left(\mathrm{m}^{2}\right)$

$A_{\mathrm{R}} \quad$ Orifice area of reed valve $\left(\mathrm{m}^{2}\right)$

$C \quad$ Hydraulic compliance

$C_{\mathrm{d}} \quad$ Discharge coefficient (0.6)

$c_{1}, c_{2} \quad$ Damping constant of return spring and band brake $\left(\mathrm{N} \mathrm{s} \mathrm{m}^{-1}\right)$

$c_{\mathrm{p}} \quad$ Damping constant of PZT stack transducer $\left(\mathrm{N} \mathrm{s} \mathrm{m}^{-1}\right)$

$c_{\mathrm{R}} \quad$ Damping constant of reed valves $\left(\mathrm{N} \mathrm{s} \mathrm{m}^{-1}\right)$

$d_{33} \quad$ Piezoelectric constant

$e \quad$ Tracking error $(\mathrm{N})$
$F_{\text {a }} \quad$ Actuation force $(\mathrm{N})$

$F_{\mathrm{e}} \quad$ External forces $(\mathrm{N})$

$F_{\mathrm{f}} \quad$ Friction force $(\mathrm{N})$

$F_{\mathrm{d}}, \dot{F}_{\mathrm{d}} \quad$ Desired force $(\mathrm{N})$ and derivative of desired force

$f, f_{\mathrm{c}} \quad$ Pulse and control frequency $(\mathrm{Hz})$

$G_{\mathrm{c}} \quad$ Flow gain $\left(=C_{\mathrm{d}} w \sqrt{2 / \rho} K_{\mathrm{g}}\right)$

$G_{1} \quad$ Leakage flow gain

$K_{\mathrm{r}} \quad$ Opening gain of reed valve

$K_{\mathrm{g}} \quad$ Control gain

$K \quad$ Lipschitz constant

$k_{1}, k_{2} \quad$ Spring constant of return spring and band brake $\left(\mathrm{N} \mathrm{m}^{-1}\right)$

$k_{\mathrm{p}} \quad$ Stiffness of PZT stack transducer $\left(\mathrm{N} \mathrm{m}^{-1}\right)$

$k_{\mathrm{R}} \quad$ Stiffness of reed valves $\left(\mathrm{N} \mathrm{m}^{-1}\right)$

$m \quad$ Effective mass of hydraulic cylinder $(\mathrm{kg})$

$m_{\mathrm{p}} \quad$ Effective mass of PZT stack transducer $(\mathrm{kg})$

$m_{\mathrm{R}} \quad$ Effective mass of reed valve $(\mathrm{kg})$

$n \quad$ Number of multilayered PZT stack transducer 
$P_{1} \quad$ Actuation pressure $(\mathrm{Pa})$

$P_{2} \quad$ Accumulator pressure $(\mathrm{Pa})$

$P_{\mathrm{p}} \quad$ Pumping pressure $(\mathrm{Pa})$

$\triangle P \quad$ Pressure difference $(\mathrm{Pa})$

$Q_{\text {o }} \quad$ Discharge (outlet) flow rate $\left(\mathrm{cm}^{3} \mathrm{~s}^{-1}\right)$

$Q_{\mathrm{s}} \quad$ Suction (inlet) flow rate $\left(\mathrm{cm}^{3} \mathrm{~s}^{-1}\right)$

$Q_{1} \quad$ Leakage flow rate $\left(\mathrm{cm}^{3} \mathrm{~s}^{-1}\right)$

$Q_{\text {c }} \quad$ Control flow rate $\left(\mathrm{cm}^{3} \mathrm{~s}^{-1}\right)$

$T \quad$ Pulse duration time (s)

$t \quad$ Pulse period time (s)

$t_{\mathrm{d}} \quad$ Delay time (s)

$t_{1}, t_{2} \quad$ Start and finish time of feedback control interval

$u \quad$ Switching control input

$V_{\mathrm{i}}(f) \quad$ Control input voltage with pulse frequency $f$

$V_{\mathrm{o}} \quad$ Control volume of head side in double-acting cylinder $\left(\mathrm{m}^{3}\right)$

$V_{\mathrm{c}} \quad$ Control volume of pumping chamber $\left(\mathrm{m}^{3}\right)$

$w \quad$ Orifice area gradient

$x, \dot{x} \quad$ Displacement (stroke) and velocity of hydraulic cylinder $\left(\mathrm{m}, \mathrm{m} \mathrm{s}^{-1}\right)$

$x_{\mathrm{o}} \quad$ Pre-loaded length of return spring (m)

$x_{\mathrm{p}}, \dot{x}_{\mathrm{p}} \quad$ Displacement (stroke) and velocity of PZT stack transducer $\left(\mathrm{m}, \mathrm{m} \mathrm{s}^{-1}\right)$

$x_{\mathrm{s}} \quad$ Dead (fill) stroke (m)

$x_{\mathrm{R}} \quad$ Opening displacement of reed valves (m)

$\alpha, \eta \quad$ Strictly positive constant

$\beta_{\mathrm{e}} \quad$ Effective bulk modulus of working fluid (Pa)

$\rho \quad$ Density of hydraulic oil $\left(\mathrm{kg} \mathrm{m}^{-3}\right)$

\section{Introduction}

An automatic transmission (in short, AT) is a critical subsystem in automotive powertrains [1]. In recent years, there has been a growing demand for cost-effective, highly efficient and reliable AT. Hence, significant research efforts have been performed and various innovative technologies have been explored to reduce the cost and improve the reliability, shift quality and fuel economy of automatic transmissions [2]. In particular, the actuation system for engaging friction elements (e.g. band brakes and clutches) is a key component to achieve good shift quality and high fuel economy [3]. However, conventional AT actuation systems have technical limitations that restrict further performance enhancement. The current systems consist of many electro-hydraulic components, such as the rotor type oil pump, the regulating valve and control valves, including the variable force solenoid (VFS) valves and pulse width modulation (in short, PWM) solenoid valves, as shown in figure 1(a). As illustrated, the structure of this type of actuation system contains two main parts: the central hydraulic power unit (i.e. the engine and rotor type oil pump) and the valve body. This structure requires distributed transmission lines to connect the valve body with each friction element, requiring fluid passage in the transmission case or fluid pipes. As a result, it negatively affects the product size and manufacturing cost of the AT. The actuation pressure is modulated through two processes in the current electrohydraulic actuation systems. The inlet flow rate from the oil pump is first regulated by the exhausting flow through the regulating valve. This regulated pressure is also controlled by the exhausting flow rate through spool valves. Such a pressure control method using continuously exhausting flow rate can negatively affect the size of the engine-driven oil pump. Furthermore, it has been recognized that the current AT friction element actuation systems have the following shortcomings.

(a) The oil pump (3-5 kg) and valve body (7-10 kg) are relatively heavy.

(b) The engine-driven oil pump causes energy loss and affects efficiency.

(c) The electromagnetic type actuator does not provide high precision controllability.

It is obvious that fuel economy will be affected by items (a) and (b), and the AT shift quality performance could be limited by item (c).

To address the aforementioned issues, various alternative actuation systems with simpler structure and compact size have been explored to replace the current AT electro-hydraulic actuation systems. For example, a two-stage actuation system was developed by combining classical actuators (DC motors) and piezoelectric actuators for automotive brakes and clutches [4]. A high force electromechanical linear actuator was developed for automated manual transmissions to satisfy the force requirement of $1 \mathrm{kN}$ over a $16 \mathrm{~mm}$ stroke [5]. Another alternative is to utilize a piezoelectric-hydraulic pump (in short, PHP). The main idea of the PHP is to combine the advantages of piezoelectric transducers (high power density and large load authority) and hydraulic systems (large stroke). It features high power density with low weight as compared with conventional actuators. In the last decade, several prototypes of piezoelectric-hydraulic pump-based actuators have been introduced by researchers [6-9]. Kim and Wang [10, 11] have built upon previous studies and explored the feasibility of synthesizing a self-contained PHP-based actuation system for AT shift control (figure 1(b)). Compared with the conventional electro-hydraulic actuation systems for AT, this new idea allows for distributed power-by-wire operation through the individual PHP-based actuation system. Compact PHPs can be utilized and the traditional components (such as the oil pump, control valves and fluid lines) are eliminated from the AT. This concept can eventually reduce the complexity, weight and fuel consumption of the current automotive transmissions. More advanced AT shift strategies, such as clutch-to-clutch control, can also be implemented more easily by using this new type of actuation system.

\section{Problem statement, objective and overall approach}

In this study, a band brake friction element integrated with a prototype PHP-based actuation system is considered as a test bed. A typical $1 \rightarrow 2$ up-shift process of an AT using a band brake is shown in figure 2 , where the shift event can be divided into three stages: the fill phase, the torque phase and the inertia phase [12]. For a complete shift, the pump flow rate should be sufficient to ensure a short fill time that is approximately $0.3 \mathrm{~s}$. In order to fill the dead stroke volume (in this case 


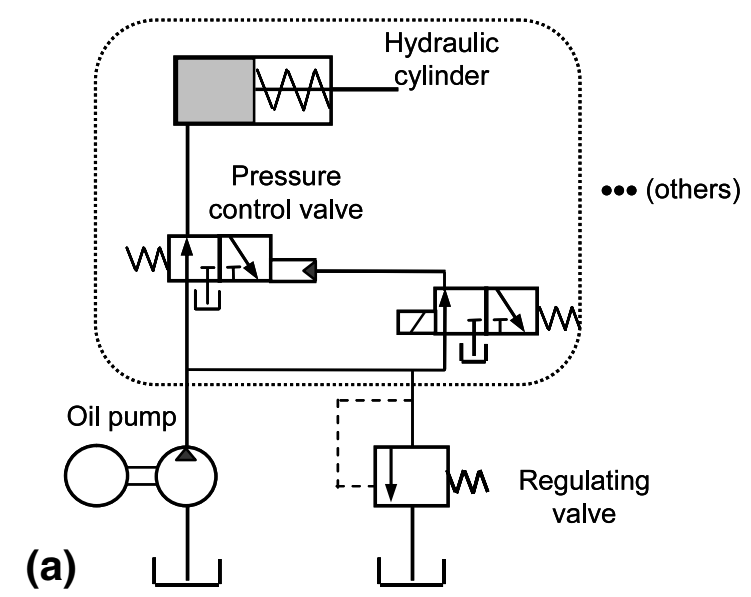

(b)

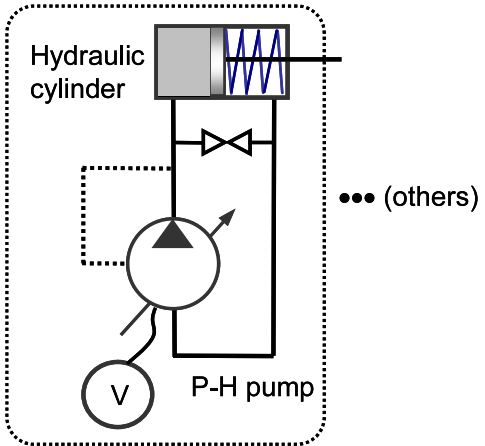

Figure 1. Comparison of two friction element actuation systems. (a) Conventional electro-hydraulic system. (b) New power-by-wire system.

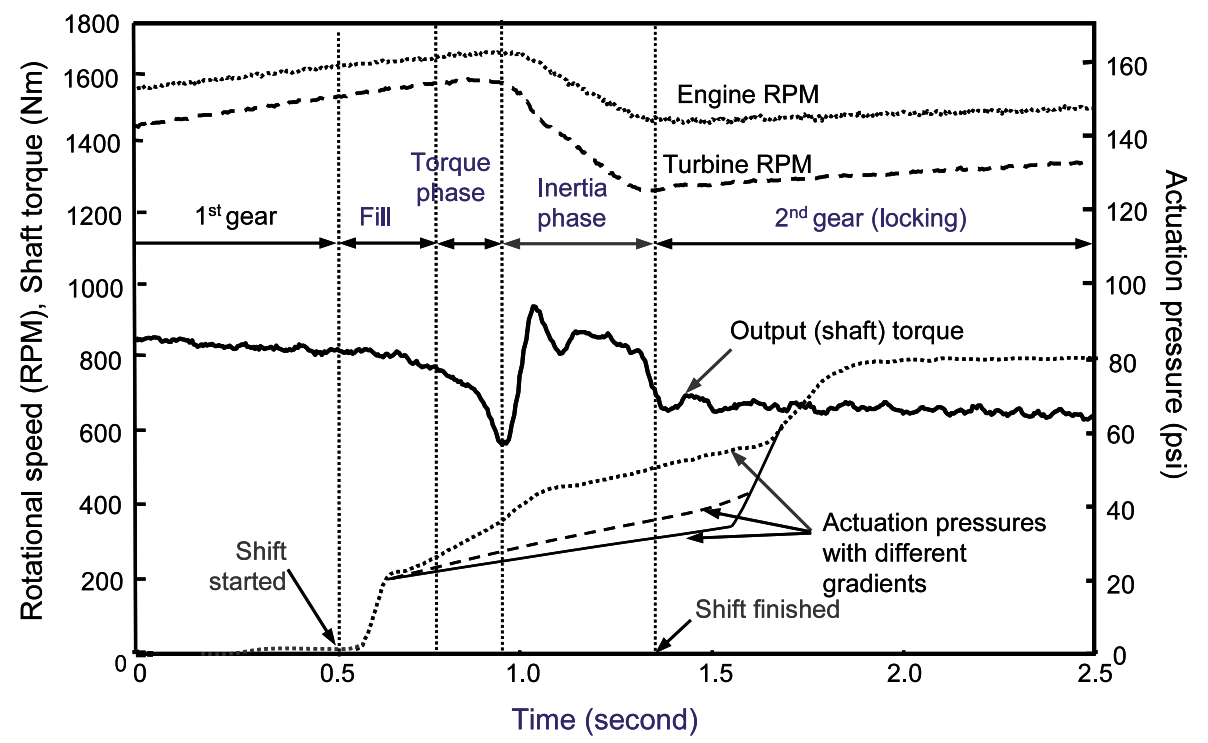

Figure 2. Typical $1 \rightarrow 2$ up-shift diagram of AT using one-way clutch and band brake.

study: $3.5 \mathrm{~mm} \times \phi 50 \mathrm{~mm}$ ) of the current servo cylinder of AT within the desired fill time, the corresponding required flow rate should be around $20 \mathrm{~cm}^{3} \mathrm{~s}^{-1}$. In the inertial phase, the actuation pressure should be controlled so that the transient output (shaft) torque can be changed smoothly. To ensure a complete shift, about $700 \mathrm{~N}$ of force is required to engage the band brake. For the given prototype PHP, the required pressure will be in the range of $0.35 \mathrm{MPa}$ to achieve such an engagement force. After the shift is completed, higher pressure is required to prevent slippage of the band brakes.

A standalone prototype PHP-based actuation system that can satisfy the aforementioned performance requirements has been designed and developed. The hardware arrangement for an AT shift control-oriented hydraulic circuit is illustrated in figure 3 [10], which consists of a PZT stack transducer, a gas accumulator and a hydraulic cylinder connecting to the band brake. The PZT transducer will be actuated with high frequency and its motion will be transformed into a large displacement, low frequency stroke of the hydraulic cylinder piston to engage the band brake. The gas accumulator is primarily used to provide pumping. Additionally, it provides various essential functions, which include cavitation prevention, pre-loading to the PZT stack transducer and improvement of dead-head pressure. A hydraulic transmission line is connected to the chambers on both sides of the doubleacting hydraulic cylinder to cancel the initial force caused by the accumulator pressure. Since bidirectional actions are not required for AT shift control, the closed-type on-off solenoid valve is incorporated for releasing the actuating pressure. When this return valve opens, the pressures become equal and the piston will be returned by the spring force.

With this circuit, a self-contained compact prototype is fabricated, as shown in figure 4 [11]. New design improvements have recently been performed on the prototype reported in [10]. For example, a compact hydraulic cylinder with a $\phi 50 \mathrm{~mm}$ bore has been customized to reduce the stickslip friction forces between the piston and the cylinder, since large stick-slip friction forces will affect the flow rate and force tracking control performance. In order to minimize these friction forces, the tight o-ring in the piston is replaced 


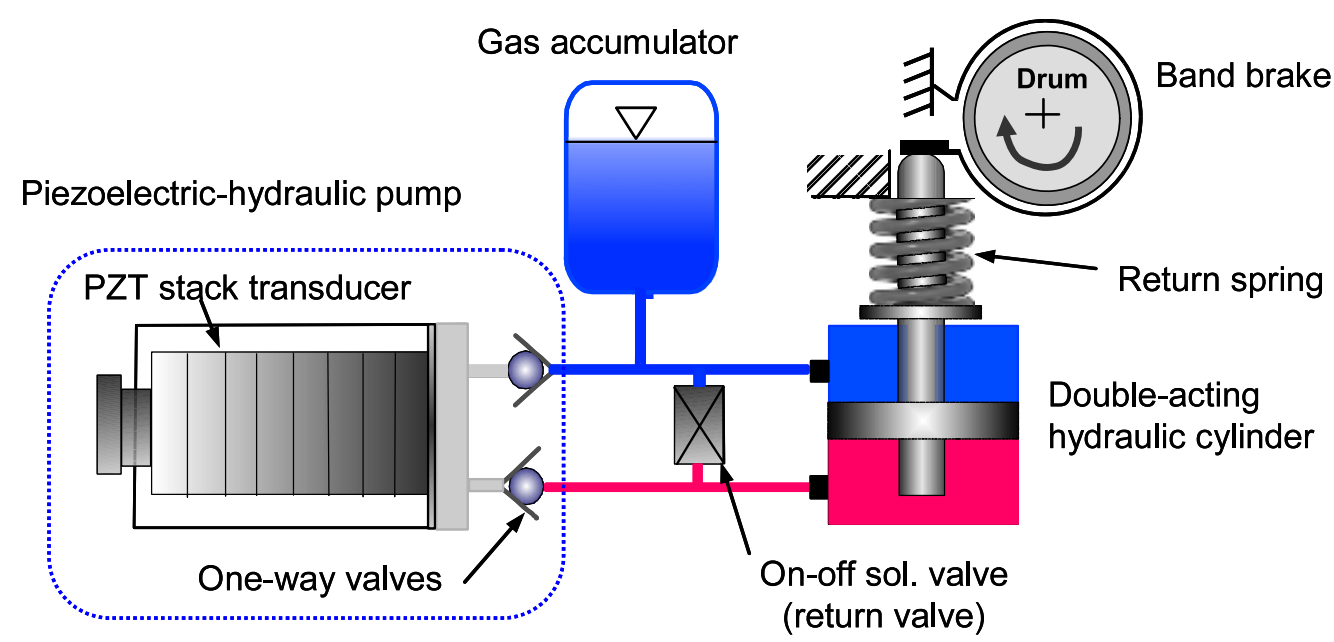

Figure 3. Hardware configuration of piezoelectric-hydraulic pump-based actuation system.
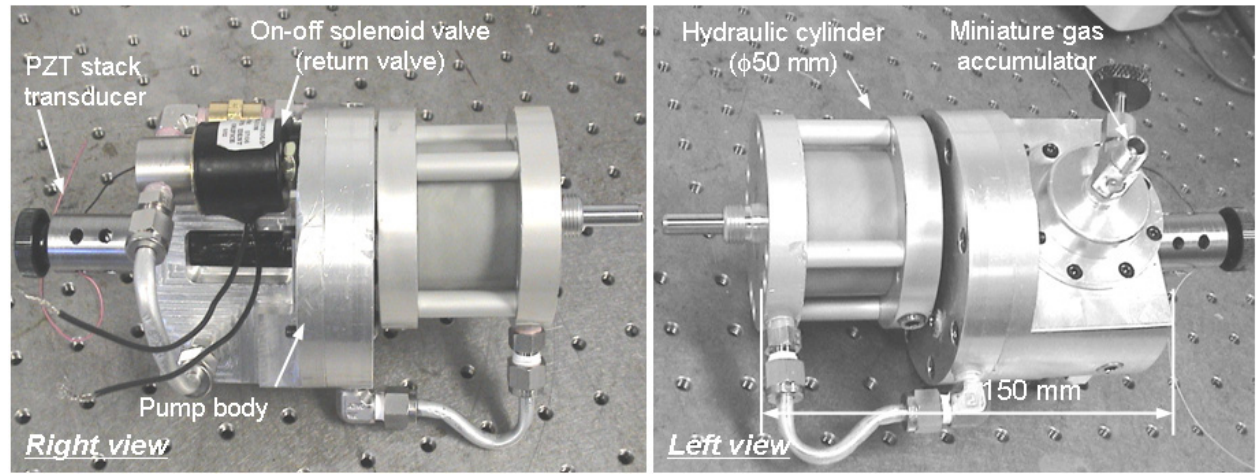

Figure 4. Photographs of fabricated standalone prototype.

with a low friction U-cup seal and the diameter of the piston is reduced from 20 to $8 \mathrm{~mm}$. The key performance of the fabricated prototype has been evaluated experimentally. Waterbased Hydrolubric ${ }^{\circledR}$ oil is used as the working oil for its high effective bulk modulus.

The measured flow rate performance under $0.55 \mathrm{MPa}$ accumulator pressure is shown in figure 5(a). When the pulse input voltage $(120 \mathrm{~V})$ is applied with different driving frequencies $(0-250 \mathrm{~Hz})$, the flow rate is proportional to the driving frequency up to $230 \mathrm{~Hz}$. As a result, this prototype actuator can achieve a maximum flow rate of $19 \mathrm{~cm}^{3} \mathrm{~s}^{-1}$ around $230 \mathrm{~Hz}$, which is sufficient to satisfy the required fill time of the test bed friction element. The maximum pressure difference shown in figure 5(b) that can be generated is 0.48 MPa under an accumulator pressure of $0.7 \mathrm{MPa}$, which is adequate for completing the shift.

With the promising design of the PHP-based actuation system, the goal of this research is to develop a controller that can effectively control the new actuator so that the required output force (pressure) profile can be generated to guarantee a smooth and reliable AT shift. The major challenge here is that the PHP-based actuation system is highly nonlinear. The technical objective is therefore to synthesize an effective nonlinear control law that can command the piezoelectric stack actuation so that the actuation system can track a certain force profile and actuate the band brake for AT shift control. To achieve the research goal, a model of the PHP-based actuation system is developed (section 3 ) and a controller is synthesized based on the sliding-mode theory and the derived system model (section 4). The PHP-based actuation system and controller are implemented and tested in a lab environment to validate the analytical predictions and demonstrate the effectiveness of the controller (section 5).

\section{System model}

To design the controller, a model of the PHP-based actuation system integrated with the friction element is first developed. The complete PHP-based actuation system consists of the PHP, the double-acting hydraulic cylinder and the emulated band brake, as shown in figure 6.

The governing equations of the cylinder piston can be expressed as

$$
m \ddot{x}=F_{\mathrm{a}}-F_{\mathrm{e}}-F_{\mathrm{f}}
$$

where $x$ represents the displacement of the piston, $m$ is the effective mass of the cylinder with piston rod, $F_{\mathrm{f}}$ is the friction force between the piston and the cylinder, $F_{\mathrm{e}}$ is the load from the band brake and $F_{\text {a }}$ represents the actuation force, which 

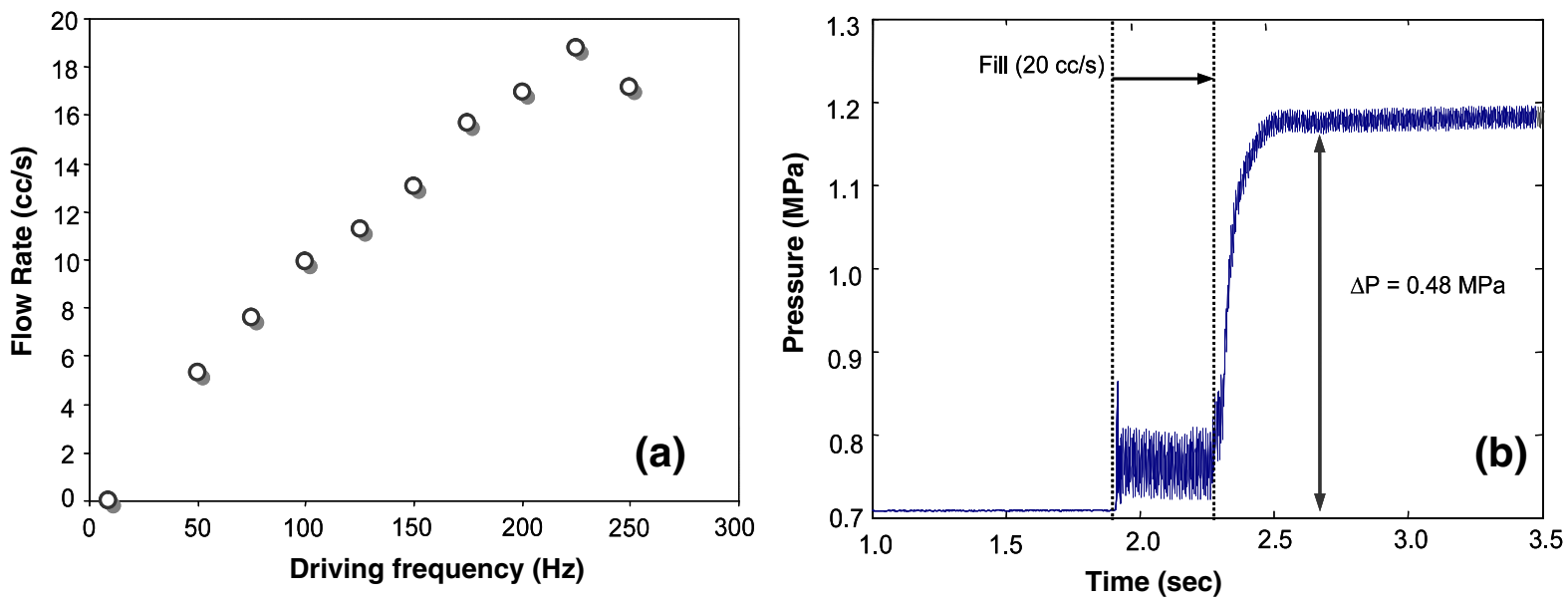

Figure 5. Performance evaluation results of prototype. (a) Flow rate $\left(P_{\mathrm{a}}=0.55 \mathrm{MPa}, 120 \mathrm{~V}\right)$. (b) Dead-head pressure $\left(P_{\mathrm{a}}=0.7 \mathrm{MPa}\right.$, $150 \mathrm{~V})$.

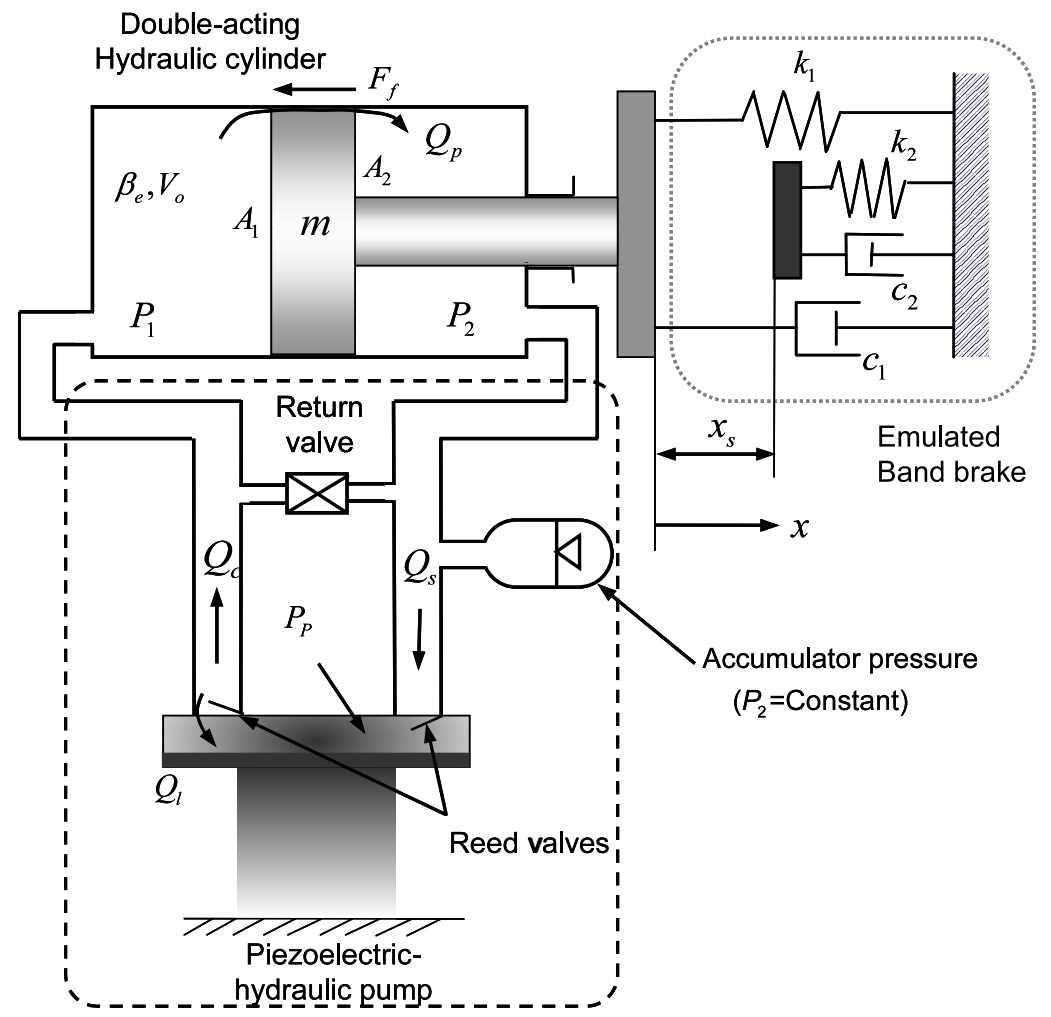

Figure 6. Schematic diagram of PHP actuation system integrated with band brake.

is the force difference between the two pressure sides in the hydraulic cylinder:

$$
F_{\mathrm{a}}=A_{1} P_{1}-A_{2} P_{2} \text {. }
$$

To represent the band brake, a double spring mechanism (spring constants $k_{1}$ and $k_{2}$ ) is introduced. During the fill (stroking) stage, the load is from the return spring force with low stiffness $\left(k_{1}\right)$. The piston will be nearly stopped after contacting the second spring (much higher stiffness $k_{2}$ ). That is, after the fill stage, the load is mainly dominated by the reaction force of the band brake:

$F_{\mathrm{e}}= \begin{cases}k_{1}\left(x+x_{\mathrm{o}}\right)+c_{1} \dot{x} & \text { if } x \leqslant x_{\mathrm{s}} \\ k_{1}\left(x+x_{\mathrm{o}}\right)+k_{2}\left(x-x_{\mathrm{s}}\right)+\left(c_{1}+c_{2}\right) \dot{x} & \text { if } x>x_{\mathrm{s}}\end{cases}$

where $k_{1}$ and $k_{2}$ are the spring constant of the return spring and the band brake, respectively. $c_{1}$ and $c_{2}$ are the damping constants of the return spring and the band brake, respectively. $x_{\mathrm{o}}$ and $x_{\mathrm{s}}$ represent the pre-loaded length and dead stroke, respectively. The actuation pressure $\left(P_{1}\right)$ is governed by the 

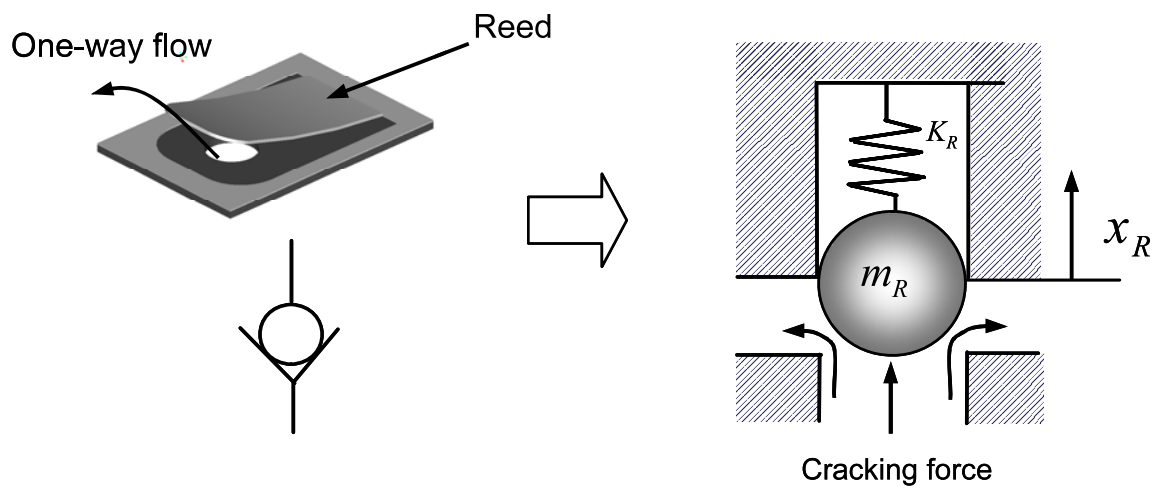

Figure 7. Single degree of freedom lumped parameter model for reed valves.

following pressure rise rate (i.e. continuity) equation:

$$
\begin{aligned}
\dot{P}_{1} & =\frac{1}{C}\left[Q_{\mathrm{o}}-Q_{1}-Q_{\mathrm{p}}-A_{1} \dot{x}\right] \\
& =\frac{\beta_{\mathrm{e}}}{\left(V_{\mathrm{o}}+A_{1} x\right)}\left[Q_{\mathrm{o}}-Q_{1}-Q_{\mathrm{p}}-A_{1} \dot{x}\right],
\end{aligned}
$$

where $\beta_{\mathrm{e}}$ is the effective bulk modulus, $V_{\mathrm{o}}$ is the control volume of the high pressure (head) side and $A_{1}$ is the ram (effective) area of the double-acting cylinder. $x$ and $\dot{x}$ represent the displacement and velocity of the piston, respectively. Note that the stick-slip friction force $\left(F_{\mathrm{f}}\right)$ in equation $(1)$ and the leakage flow across the piston $\left(Q_{\mathrm{p}}\right)$ in equation (4) are considered to be negligible. The pre-charged accumulator pressure $\left(P_{2}\right)$ of the rod side is assumed to be constant in this paper. $Q_{\mathrm{o}}$ is the outlet (discharging) flow rate, $Q_{1}$ and $Q_{\mathrm{p}}$ denotes the leakage flow rate across the outlet reed valve and cylinder piston, respectively. These flow rates can be determined by the following orifice equation:

$$
Q=\operatorname{sgn}(\Delta P) \cdot C_{\mathrm{d}} A_{\mathrm{o}} \sqrt{\frac{2|\Delta P|}{\rho}},
$$

where $C_{\mathrm{d}}$ is the discharging flow coefficient, $A_{\mathrm{o}}$ is the orifice area and $\Delta P$ is the pressure difference between up-stream and down-stream. To specify the outlet flow rate, the pumping pressure $\left(P_{\mathrm{p}}\right)$ of the PHP is introduced by the continuity equation of the pumping chamber as follows:

$$
\dot{P}_{\mathrm{p}}=\frac{\beta_{\mathrm{e}}}{\left(V_{\mathrm{c}}+A_{\mathrm{p}} x_{\mathrm{p}}\right)}\left(Q_{\mathrm{o}}-Q_{\mathrm{s}}-A_{\mathrm{p}} \dot{x}_{\mathrm{p}}\right)
$$

where $V_{\mathrm{c}}$ is the pumping chamber volume, and $x_{\mathrm{p}}$ and $\dot{x}_{\mathrm{p}}$ are the displacement (stroke) and velocity of the PZT stack, respectively. $A_{\mathrm{p}}$ is the area of the diaphragm and $Q_{\mathrm{s}}$ is the inlet (suction) flow rate. Once the pumping pressure is generated by stroking the PZT stack transducer, the outlet flow rate and the inlet flow rate through the two reed valves can be expressed by the orifice equations as follows:

$$
\begin{array}{r}
Q_{\mathrm{o}}=C_{\mathrm{d}} w \cdot x_{\mathrm{R}} \sqrt{\frac{2}{\rho}} \sqrt{P_{\mathrm{p}}-P_{1}}, \\
x_{\mathrm{R}}= \begin{cases}x_{\mathrm{R}} & \text { if } x_{\mathrm{R}} \geqslant 0 \\
0 & \text { if } x_{\mathrm{R}}<0,\end{cases}
\end{array}
$$

$$
\begin{array}{r}
Q_{\mathrm{s}}=C_{\mathrm{d}} w \cdot x_{\mathrm{R}} \sqrt{\frac{2}{\rho}} \sqrt{P_{2}-P_{\mathrm{p}}}, \\
x_{\mathrm{R}}= \begin{cases}x_{\mathrm{R}} & \text { if } x_{\mathrm{R}} \leqslant 0 \\
0 & \text { if } x_{\mathrm{R}}>0,\end{cases}
\end{array}
$$

where $w$ is the orifice area gradient and $x_{\mathrm{R}}$ represents the opening displacement of the reed valve. As shown in figure 7, due to the one-way valve action, the backward flow can be zero during discharging or suction, which leads to the elimination of the sign function in equation (5).

The PZT stack model can be reduced to a single degree of freedom static model, since the response time of the PZT stack transducer (approximately $200 \mu$ s for the square pulse of $200 \mathrm{~V} \mathrm{[13])} \mathrm{is} \mathrm{much} \mathrm{shorter} \mathrm{than} \mathrm{the} \mathrm{operating} \mathrm{pulse}$ duration time (5000 $\mu$ s corresponding to $200 \mathrm{~Hz}$ ) and the operational frequency $(1-200 \mathrm{~Hz})$ is much lower than the first natural frequency of the PZT stack used in this study (e.g. about $20 \mathrm{kHz}$ ). By also neglecting the pressure pre-load, the displacement of the PZT stack transducer $\left(x_{\mathrm{p}}\right)$ is given by the following equation:

$$
x_{\mathrm{p}}=K_{\mathrm{p}} V_{\mathrm{i}}(f)
$$

where $V_{\mathrm{i}}(f)$ is the input voltage and $K_{\mathrm{p}}=n k_{\mathrm{p}} d_{33}, n$ is the number of stack layers, $d_{33}$ is the piezoelectric coupling coefficient and $k_{\mathrm{p}}$ is the effective stiffness of the PZT stack that can be derived from the linear constitutive law of the piezoelectric material.

For the reed valve opening $\left(x_{\mathrm{R}}\right)$ in equations (7) and (8), the reed dynamics is also described as a single degree of freedom lumped model, based on the fact that the nominal operating frequency is lower than the bandwidth of the reed $(400 \mathrm{~Hz})$ and will not excite the higher-order modes of the reed valve. The governing equation of the reed opening displacement becomes

$$
m_{\mathrm{R}} \ddot{x}_{\mathrm{R}}+c_{\mathrm{R}} \dot{x}_{\mathrm{R}}+k_{\mathrm{R}} x_{\mathrm{R}}=A_{\mathrm{R}}\left(P_{\mathrm{p}}-P_{1}\right)
$$

where $A_{\mathrm{R}}\left(P_{\mathrm{p}}-P_{1}\right)$ is the cracking force, and $m_{\mathrm{R}}, c_{\mathrm{R}}, k_{\mathrm{R}}$ and $A_{\mathrm{R}}$ represent the effective mass, the damping constant and the effective stiffness and the orifice $(\phi=3 \mathrm{~mm})$ area of the reed valve, respectively. With this approximation, the reed valve can 

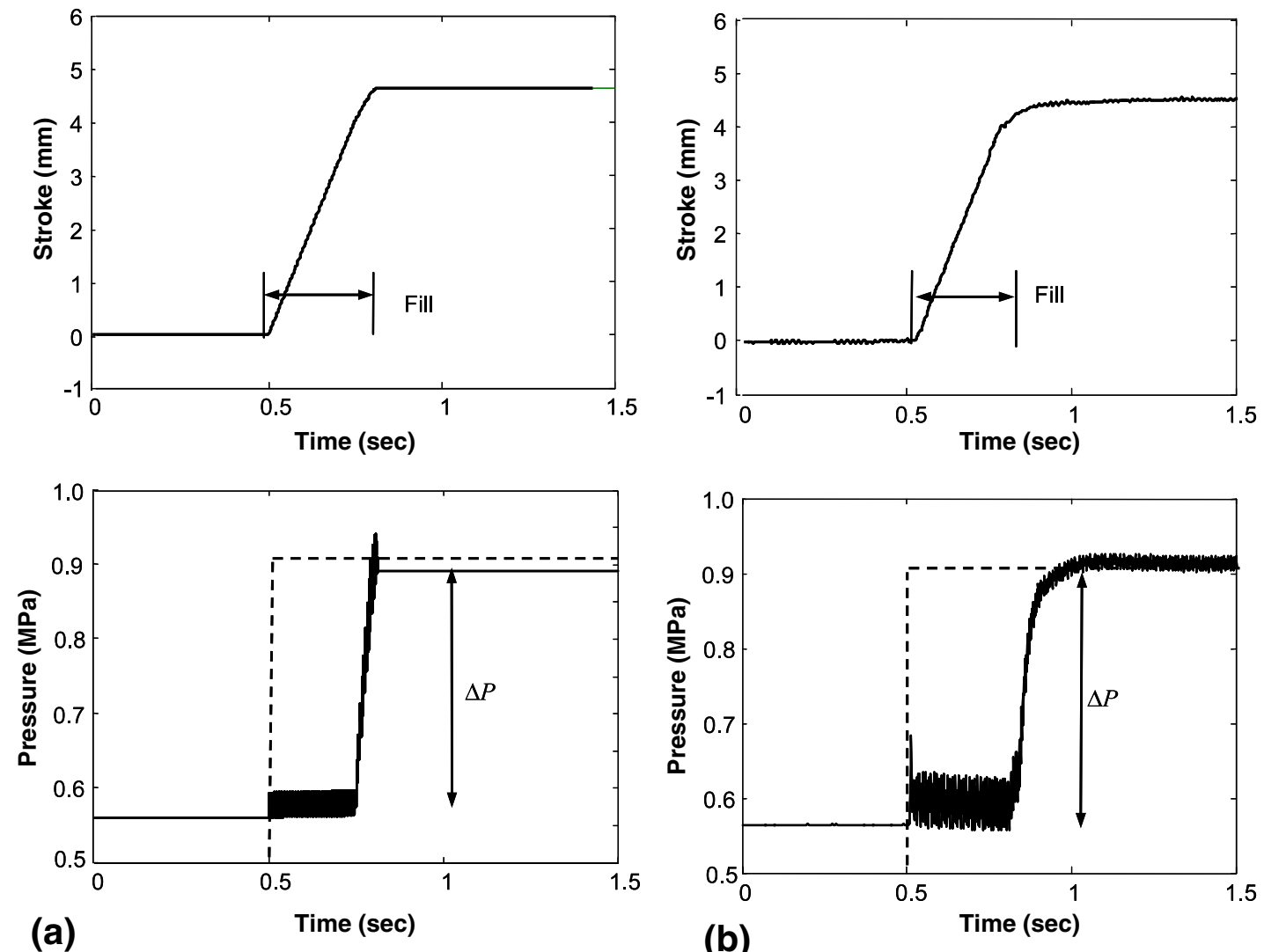

Figure 8. Open-loop step response of band brake actuation system with PHP actuation system (0.55 MPa accumulator pressure, --- ; step input of $120 \mathrm{~V}$ with $200 \mathrm{~Hz}$ ). (a) Simulation. (b) Experiment.

be modeled as a check ball valve, as shown in figure 7 . This check valve model can be further simplified since the opening displacement of the reed is limited by the stopper to prevent excessive deformation, which will affect the fatigue limit of spring steel reeds. In other words, it is nearly an on-off motion without transient dynamics:

$$
x_{\mathrm{R}}=K_{\mathrm{r}} \Delta P=K_{\mathrm{r}} K_{\mathrm{c}} x_{\mathrm{p}},
$$

where $K_{\mathrm{r}}$ is the opening gain. This assumption can be verified by experimental results. As shown, the measured flow rate in figure 5(a) shows good linearity with respect to the driving frequency, which implies that the orifice opening area of the reed valve is constant in the low frequency range (below $200 \mathrm{~Hz}$ ) due to the wide opening. With the developed system model, open-loop response is first simulated and compared with experimental results to confirm the performance of the PHP-based actuation system and to validate the derived system model, as shown in figure 8 . The simulation parameters and dimensions are listed in table 1 . When a step input (120 V, $200 \mathrm{~Hz}$ ) is applied, the fill time for a $4 \mathrm{~mm}$ stroke is $0.27 \mathrm{~s}$ (simulation) to $0.3 \mathrm{~s}$ (experiment), which corresponds to a flow rate of $19-20 \mathrm{~cm}^{3} \mathrm{~s}^{-1}$. The generated maximum pressure difference $(\Delta P)$ is about $0.35 \mathrm{MPa}$ in both cases, which converts to an output force of $700 \mathrm{~N}$. It is shown that the analysis and experimental results are in good agreement.

\section{Control law development}

For controller design, a few assumptions are made based on the experimental results. The pumping pressure rise dynamics (i.e. equation (6)) is first of all neglected since the actuation system is mainly operating under steady state. While the actual pumping pressure is oscillating due to the pulsed operation of the pump, as shown in figure 9, only the discharging flow rate is considered for controller design since the control action is only performed while discharging. The RMS averaging value of the discharging pulse (i.e. the upper part) is used to approximate the pumping pressure, which is proportional to the stroke of the PZT stack $\left(x_{\mathrm{p}}\right)$ in equation (6) under the same accumulator pressure.

Substituting equation (9) into equation (11), the opening displacement of the inlet reed valve can be treated as the control input:

$$
x_{\mathrm{R}}=K_{\mathrm{r}} \cdot K_{\mathrm{c}} x_{\mathrm{p}}=K_{\mathrm{r}} K_{\mathrm{c}} K_{\mathrm{p}} \cdot V_{\mathrm{i}}(f)=K_{\mathrm{g}} V_{\mathrm{i}}(f),
$$

where $V_{\mathrm{i}}(f)$ is the control input voltage pulse (120 V of frequency $f_{\mathrm{c}}$ ) and $K_{\mathrm{g}}$ is the final control gain. By introducing these assumptions, the final governing equations for designing 


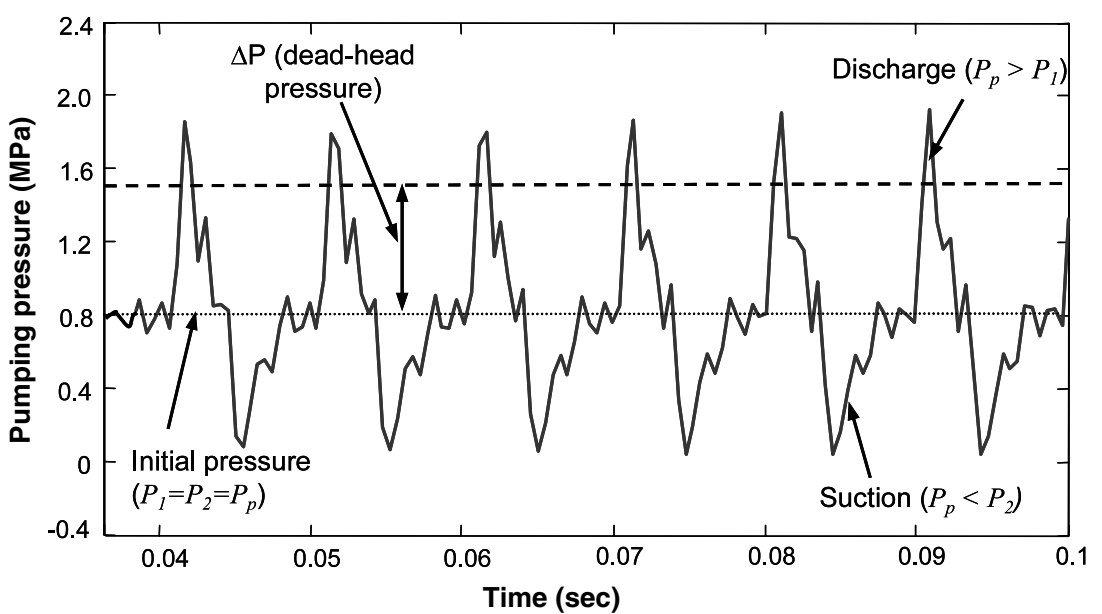

Figure 9. Alternating wave patterns of measured pumping pressure (100 Hz; ---: approximated pressure).

Table 1. Simulation parameters, dimensions and gains for actuation force control.

\begin{tabular}{|c|c|c|}
\hline Symbol & Items (SI unit) & Nominal value \\
\hline$A_{1}$ & $\begin{array}{l}\text { Ram (effective) area of head side in double-acting } \\
\text { hydraulic cylinder }\left(\mathrm{m}^{2}\right)\end{array}$ & 0.002 \\
\hline$A_{2}$ & $\begin{array}{l}\text { Ram area (effective) area of rod side in } \\
\text { double-acting hydraulic cylinder }\left(\mathrm{m}^{2}\right)\end{array}$ & 0.0019 \\
\hline$C_{\mathrm{d}}$ & Discharge coefficient & 0.6 \\
\hline$c_{1}, c_{2}$ & $\begin{array}{l}\text { Damping constant of return spring and band brake } \\
\left(\mathrm{N} \mathrm{s} \mathrm{m}^{-1}\right)\end{array}$ & 1 (assumed) \\
\hline$P_{\mathrm{c}}$ & Pressure of pumping chamber (MPa) & 1.2 \\
\hline$P_{2}$ & Pressure of accumulator (MPa) & 0.55 \\
\hline$K_{\mathrm{g}}$ & Control gain & 0.0045 \\
\hline$G_{1}$ & Leakage flow gain & $2 \times 10^{-7}$ \\
\hline$k_{1}$ & Spring constant of return spring $\left(\mathrm{N} \mathrm{m}^{-1}\right)$ & 39 \\
\hline$k_{2}$ & Spring constant of band brake $\left(\mathrm{N} \mathrm{m}^{-1}\right)$ & $3 \times 10^{5}$ (assumed) \\
\hline$m$ & Effective mass of hydraulic cylinder $(\mathrm{kg})$ & 0.01 \\
\hline$V_{\mathrm{o}}$ & $\begin{array}{l}\text { Control volume of head side in double-acting } \\
\text { cylinder }\left(\mathrm{m}^{3}\right)\end{array}$ & $8 \times 10^{-4}$ \\
\hline$w$ & Reed orifice area gradient & 0.0094 \\
\hline$x_{\mathrm{o}}$ & Pre-loaded length of return spring $(\mathrm{m})$ & 0.003 \\
\hline$x_{\mathrm{s}}$ & Dead (fill) stroke (m) & 0.004 \\
\hline$x_{\mathrm{R}}$ & Opening displacement of reed valves (m) & 0.001 \\
\hline$\beta_{\mathrm{e}}$ & Effective bulk modulus of working fluid (MPa) & 400 \\
\hline$\rho$ & Density of hydraulic oil $\left(\mathrm{kg} \mathrm{m}^{-3}\right)$ & 860 \\
\hline
\end{tabular}

the controller can be expressed as

$$
\begin{gathered}
\dot{x}_{1}=x_{2} \quad \dot{x}_{2}=\frac{1}{m}\left(F_{\mathrm{a}}-F_{\mathrm{e}}\right) \\
\dot{x}_{3}=\frac{\beta_{\mathrm{e}}}{\left(V_{\mathrm{o}}+A_{1} x_{1}\right)}\left[G_{\mathrm{c}} \sqrt{P_{\mathrm{p}}-x_{3}} \cdot V_{\mathrm{i}}(f)-Q_{1}-A_{1} x_{2}\right],
\end{gathered}
$$

where $x_{1}$ is the cylinder displacement (stroke), $x_{2}$ is the cylinder velocity, $x_{3}$ is the actuation pressure $\left(P_{1}\right), G_{\mathrm{c}}(=$ $\left.C_{\mathrm{d}} w \sqrt{2 / \rho} K_{\mathrm{g}}\right)$ is the flow gain and $Q_{1}\left(=G_{1} \sqrt{P_{1}-P_{2}}\right)$ is the leakage flow rate in the outlet reed valve, which is zero while discharging. Since the output of interest here is the actuation force, the output is $y=A_{1} x_{3}-A_{2} P_{2}$.

Two separate controllers are designed for the two governing motions of the actuation system during the fill phase and the actuation stage, respectively. During the fill stage $\left(x \leqslant x_{\mathrm{s}}\right.$ ), based on the concept of minimum time control resulting from the shortest fill time requirement, open-loop Bang-Bang control is applied until the end of the fill:

$$
V_{\mathrm{i}}=V_{\mathrm{i}}\left(f_{\max }\right)
$$

In order to develop the nonlinear tracking control law during the actuation stage $\left(x>x_{\mathrm{s}}\right)$, a sliding-mode controller is designed [16]:

$$
u=u_{\text {eq }}+u_{\text {switching }},
$$

where $u_{\text {eq }}$ is the equivalent feedback control input to reach the state on the sliding surface and $u_{\text {switching }}$ is the discontinuous control input to keep the state on the sliding surface to ensure robustness. Unlike the standard tacking control problem, the equivalent control input term, however, can be ruled out for AT shift control since the initial state (i.e. initial force) always coincides with the desired reference trajectory, as shown in 
figure 2 . Now, define the sliding surface for the derived system model ( $n=3$ in this case):

$$
s=\left(\frac{\mathrm{d}}{\mathrm{d} t}+\lambda\right)^{n-1} \cdot e=\ddot{e}+2 \lambda \dot{e}+\lambda^{2} e
$$

where $e$ is a force tracking error between the desired actuation force $\left(F_{\mathrm{d}}\right)$ and the actual actuation force (i.e. $\left.e=F_{\mathrm{d}}-F_{\mathrm{a}}\right)$ and $\lambda$ is the strictly positive constant. This sliding surface design requires many differentiation operators, which are impractical in AT controller implementation. This difficulty can be reduced using a reduced order sliding surface $(s=e)$ with only the third equation of equation (13), based on the fact that the control input $\left(V_{\mathrm{i}}(f)\right)$ appears explicitly in the output state. Once the PHP actuator generates sufficient control flow rate (i.e. $G_{\mathrm{c}} \sqrt{P_{\mathrm{p}}-x_{3}} \cdot V_{\mathrm{i}}(f)$ in equation (13)) at the beginning stage of the tracking control, the tracking error can converge along $s=0$ only by the switching control law:

$$
u=\operatorname{sgn}(s)
$$

This simple but effective controller can be interpreted physically. If the actual force is lower than the desired actuation force ( $e=F_{\mathrm{d}}-F_{\mathrm{a}}>0$ ), it is clear that the actual force can be raised by increasing the actuation pressure through the control flow rate. If the actual force is higher than the desired force $\left(e=F_{\mathrm{d}}-F_{\mathrm{a}}<0\right)$, the actual force will be slightly dropped due to the leakage flow in the outlet reed valve. As a result, the actual force can track the desired force by switching between the two control modes. The advantage of this switching controller is that it does not require cylinder position and velocity feedback or much gain tuning. In order to convert the switching control input into pulse frequency information, the following modulating scheme is needed such that the PHP actuator will possess the aforementioned on-off switching modes:

$$
\begin{array}{cc}
\text { On mode: } V_{\mathrm{i}}=V_{\mathrm{i}}\left(f_{\mathrm{c}}\right) & \text { if } u=+1, \\
\text { Off mode: } V_{\mathrm{i}}=0 & \text { if } u=-1 .
\end{array}
$$

If the actuation force trajectory is assumed to be a differentiable function, the derivative of the actuation force yields the following equation by denoting $G_{\mathrm{c}} \sqrt{P_{\mathrm{p}}-P_{1}}$. $V_{\mathrm{i}}(f)$ in equation (13) as the control flow rate $Q_{\mathrm{c}}$, since the accumulator pressure $\left(P_{2}\right)$ is constant:

$$
\dot{F}_{\mathrm{a}}=A_{1} \dot{P}_{1}-A_{2} \dot{P}_{2}=A_{1}\left[\frac{\beta_{\mathrm{e}}}{\left(V_{\mathrm{o}}+A_{1} x\right)}\left(Q_{\mathrm{c}}-Q_{1}-A_{1} \dot{x}\right)\right] \text {. }
$$

Based on equations (18) and (19) can be rewritten as follows:

$$
\dot{F}_{\mathrm{a}}=\left\{\begin{array}{cc}
-\frac{A_{1}^{2} \beta_{\mathrm{e}}}{\left(V_{\mathrm{o}}+A_{1} x\right)} \dot{x}+\frac{A_{1} \beta_{\mathrm{e}}}{V_{\mathrm{o}}+A_{1} x} Q_{\mathrm{c}} & \\
=-A_{1} \alpha \dot{x}+\alpha Q_{\mathrm{c}}, \quad u=+1, \\
-\frac{A_{1}^{2} \beta_{\mathrm{e}}}{\left(V_{\mathrm{o}}+A_{1} x\right)} \dot{x}-\frac{A_{1} \beta_{\mathrm{e}}}{V_{\mathrm{o}}+A_{1} x} Q_{\mathrm{l}} & \\
=-A_{1} \alpha \dot{x}-\alpha Q_{\mathrm{l}}, \quad u=-1 .
\end{array}\right.
$$

The sliding surface $s \equiv 0$ is reached within a finite time when the following sliding condition for the positive constant $(\eta)$ is satisfied [15]:

$$
s \dot{s} \leqslant-\eta|s| .
$$

Substituting $\dot{s}$ into equation (21) yields the following equations:

$$
s \dot{s}= \begin{cases}s\left(-\alpha Q_{\mathrm{c}}+A_{1} \alpha \dot{x}+\dot{F}_{\mathrm{d}}\right), & u=+1, \\ s\left(\alpha Q_{1}+A_{1} \alpha \dot{x}+\dot{F}_{\mathrm{d}}\right), & u=-1 .\end{cases}
$$

Next, assume that the bounded $\dot{F}_{\mathrm{d}}, \dot{x}, \alpha$ and $Q_{1}$ (see the next paragraph for discussions) can be chosen for a given positive $\eta$ such that

$$
\begin{gathered}
\alpha Q_{1}+A_{1} \alpha \dot{x}+\dot{F}_{\mathrm{d}}>\eta \quad \text { and } \\
-\alpha Q_{\mathrm{c}}+A_{1} \alpha \dot{x}+\dot{F}_{\mathrm{d}}<-\eta .
\end{gathered}
$$

Then, if $s<0$ (i.e. $u=\operatorname{sgn}(s)=-1$ ), the following condition will always be satisfied from equations (21) and (23):

$$
s\left(\alpha Q_{1}+A_{1} \alpha \dot{x}+\dot{F}_{\mathrm{d}}\right)<\eta s<0 .
$$

Also, if $s>0$ (i.e. $u=\operatorname{sgn}(s)=+1$ ), equation (21) becomes

$$
s\left(-\alpha Q_{\mathrm{c}}+A_{1} \alpha \dot{x}+\dot{F}_{\mathrm{d}}\right)<-\eta s<0 .
$$

In both cases, the sliding condition is always satisfied. Consequently, the proposed sliding-mode controller guarantees the tracking of the desired actuation force.

It can be shown that $\dot{F}_{\mathrm{d}}, \dot{x}, \alpha$ and $Q_{1}$ are explicitly bounded to satisfy the sliding condition. First, note that the derivative of the reference force $\left(\dot{F}_{\mathrm{d}}\right)$ is always positive since negative $\dot{F}_{\mathrm{d}}$ is not required in AT shift control. Since we can design $F_{\mathrm{d}}$ with the finite Lipschitz constant $K$ such that $0<\left|\dot{F}_{\mathrm{d}}(t)\right| \leqslant K<\infty$ on the control time interval [ $\left.t_{1}, t_{2}\right], F_{\mathrm{d}}$ must be Lipschitz continuous, which implies that the derivative of $F_{\mathrm{d}}(t)$ is explicitly bounded [14]. Since the stroke of the hydraulic cylinder is also physically limited (i.e. $x_{0} \leqslant x(t) \leqslant x_{\mathrm{s}}$ ) and the stroke is changing smoothly after contacting the band brake, as shown in figure 8 , it must be Lipschitz continuous during the control interval, implying that its derivative is explicitly bounded. The effective bulk modulus in hydraulic compliance normally has some uncertainty due to pressure variation and the uncertain amount of entrapped air [16], but is bounded:

$$
\beta_{\mathrm{e} \text { min }} \leqslant \beta_{\mathrm{e}}(t) \leqslant \beta_{\mathrm{e} \max } .
$$

Since the ram area of the hydraulic cylinder and the control volume are finite values due to the design constraint, the parameter $\alpha$ is bounded by the following expressions:

$$
0<\frac{A_{1}^{2} \beta_{\mathrm{e} \min }}{\left(V_{\mathrm{o}}+A_{1} x_{\mathrm{s}}\right)} \leqslant \alpha \leqslant \frac{A_{1}^{2} \beta_{\mathrm{e} \max }}{\left(V_{\mathrm{o}}+A_{1} x_{0}\right)} .
$$

Finally, when the pump is off, the actuating pressure $P_{1}$ is always higher than the initial accumulator pressure $P_{2}$. Hence, the positive value of the leakage flow in the outlet reed valve $Q_{1}$ is also bounded by the maximum leakage flow rate $\left(Q_{1 \text { max }}\right)$ that can occur at the maximum pressure difference. 


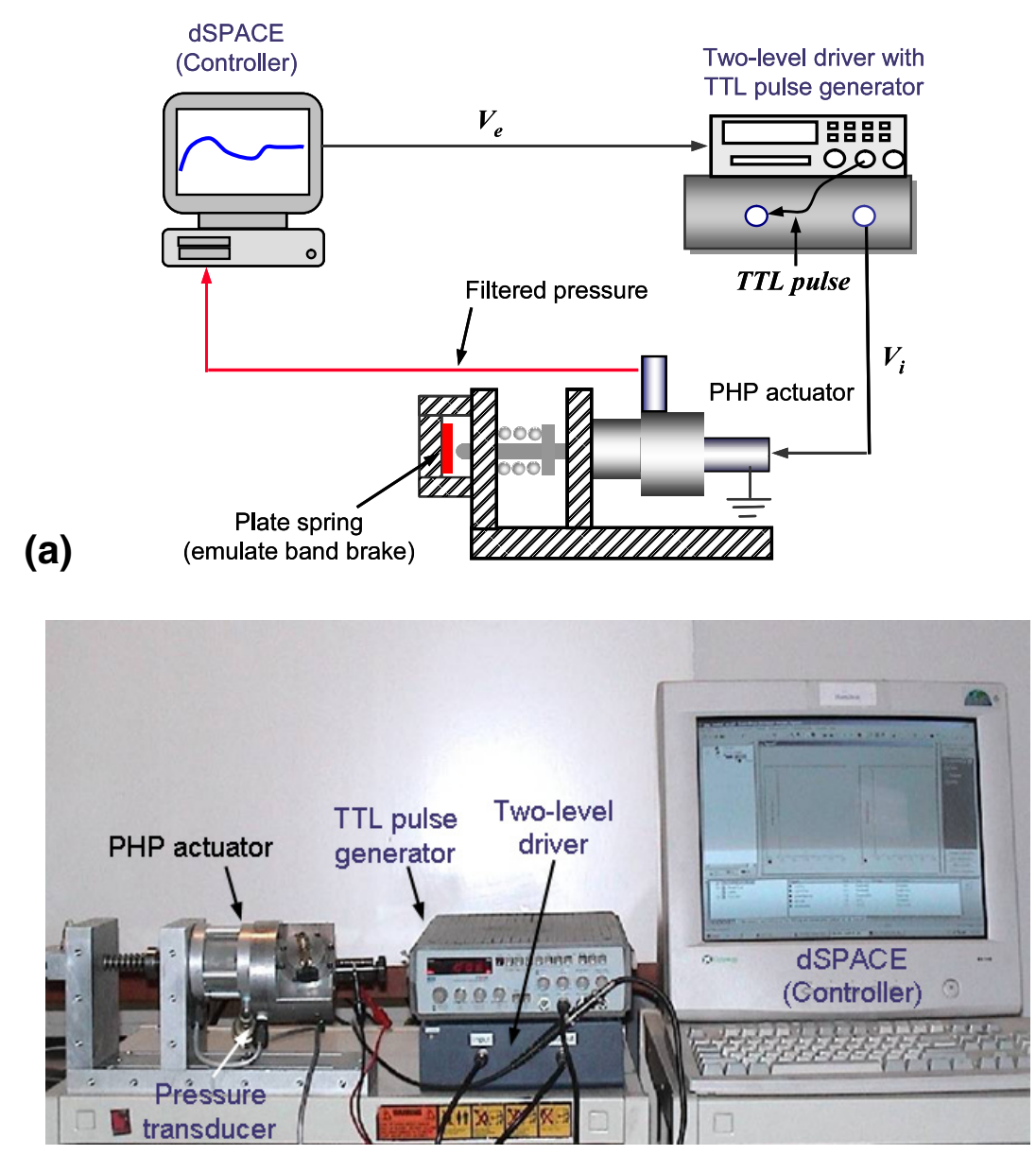

(b)

Figure 10. Experimental set-up for force tracking control of PHP-based actuation system. (a) Configuration. (b) Photograph.

\section{Experimental investigations}

To examine the effectiveness of the proposed controller, experimental studies are performed. The overall experimental set-up shown in figure 10 consists of a dSPACE system, a TTL pulse generator, a two-level driver and the PHP-based actuation system. The designed control law is implemented using the dSPACE system. The actuation pressure of interest is measured by using a pressure transducer located in the high pressure (head) side of the hydraulic cylinder. Once the control starts, a fill command of $200 \mathrm{~Hz}$ is first applied to the PHPbased actuation system for the fill stage. During the actuation stage, the measured actuation pressure will be sent to the dSPACE system. The measured actuation pressure is filtered using a low-pass filter (cutoff frequency of $20 \mathrm{~Hz}$ ) to reduce the pressure ripples caused by the pulse driven actuation of the pump.

This actuation pressure will be converted into the actuation force for the control law of equations (17) and (18). The control input voltage $\left(V_{\mathrm{i}}\right)$ is then determined. As described in section 4 , this control input, however, has to be the pulse voltage with constant amplitude and varying frequency. A two-level driver for the PZT stack transducer is used in this study. Compared with a linear power amplifier, this driver features compactness, higher efficiency and superior compensation capability for large capacitive loads (i.e. $30 \mu \mathrm{F}$ of the PZT stack) at high frequencies, which are appropriate for automotive applications. Accordingly, implementation of the control law requires an intermediate step since the customized two-level driver has to be driven by TTL (transistor-transistor logic) pulse. Therefore, the control input should be converted into the equivalent control $\left(V_{\mathrm{e}}\right)$, which in turn will be an input into the TTL pulse generator. The final control pulse input voltage (which is the same as the calculated control input $V_{\mathrm{i}}$ ) will be eventually applied to the PZT stack through the two-level driver in the circuit. The aforementioned controller implementation procedure is illustrated by the wave forms of the various control signals in figure 11.

The voltage-controlled frequency (in short, VCF) function of the TTL pulse generator is used to convert the frequency of the control input into the equivalent control input voltage. According to the sensitivity curve, the pulse frequency of the control input will be proportionally converted into the equivalent control input as follows:

$$
V_{\mathrm{e}}=0.05 f_{\mathrm{c}},
$$

where $f_{\mathrm{c}}$ is the control pulse frequency, which will be the TTL pulse frequency. 


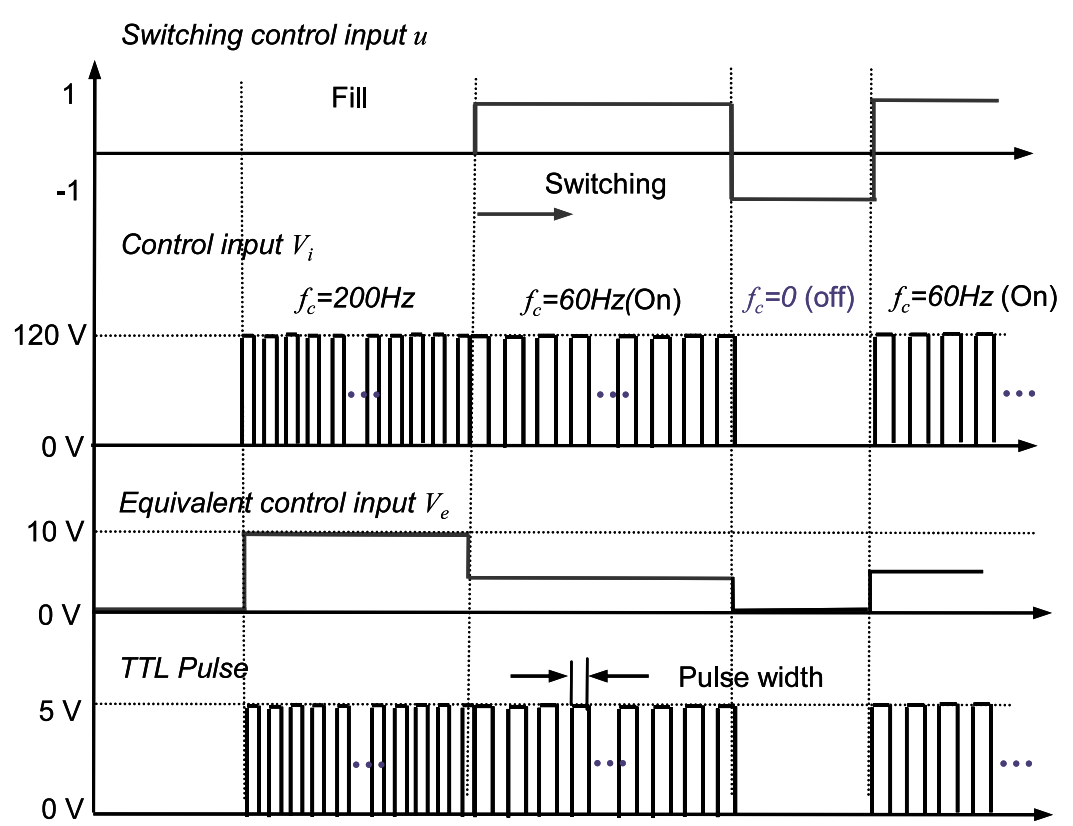

Figure 11. Wave forms of individual control signals.

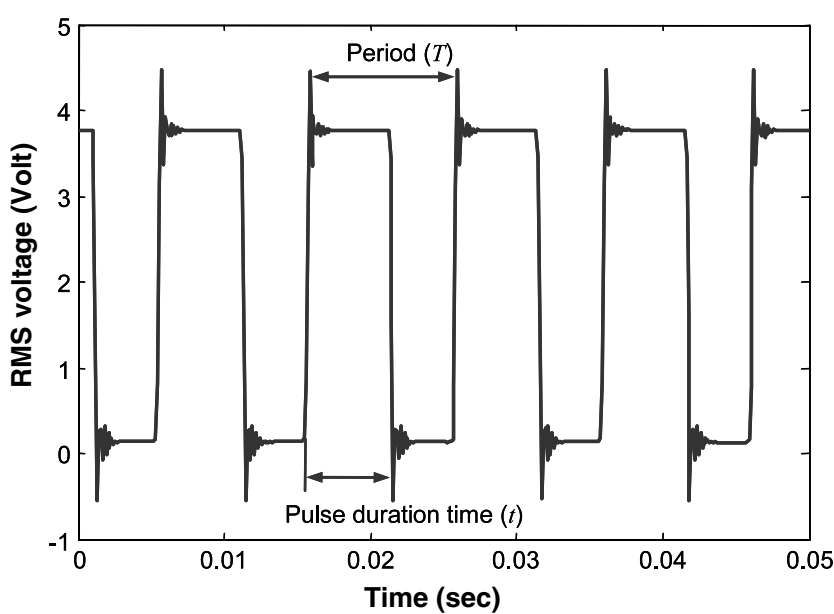

Figure 12. TTL pulse input for two-level driver: $100 \mathrm{~Hz}, 60 \%$ duty ratio, rise and fall time $(<24 \mathrm{~ns})$.

An example of the TTL pulse is illustrated in figure 12 . Since the opening time of the reed valve is directly related to the pressure characteristic and its ability to generate the deadhead pressure [9], an optimum pulse width of the TTL pulse input is determined experimentally. In general, the pulse width of the TTL pulse is defined as the following duty ratio:

$$
\text { Duty ratio }=\frac{t}{T} \times 100(\%),
$$

where $T$ is the time period and $t$ is the pulse duration time. Based on the comparison results for various duty ratios, the duty ratio of the TTL pulse is chosen to be $60 \%$, since it shows the largest pressure difference under normal operational conditions.

The customized two-level driver switches a large capacitive load between a low level (e.g. $0 \mathrm{~V}$ ) and a high level

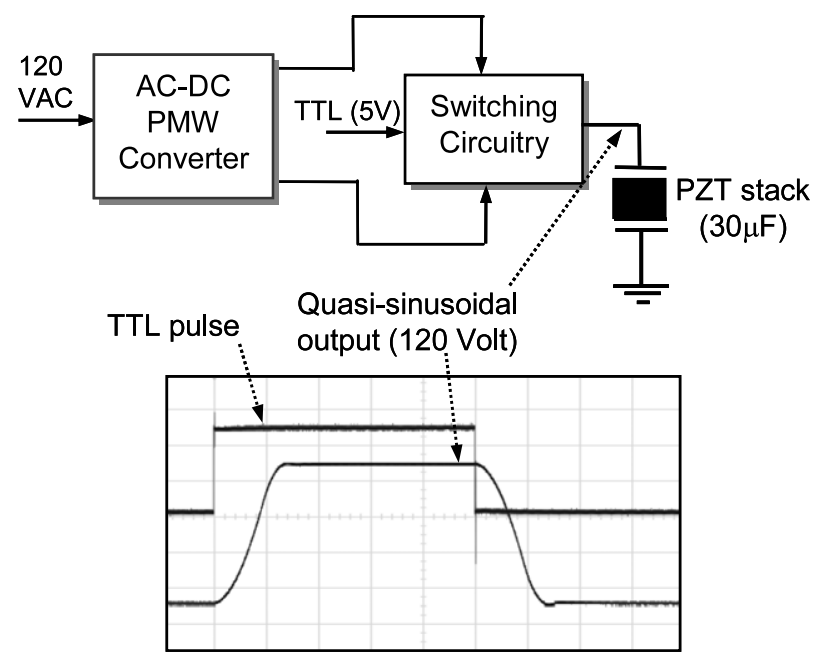

Figure 13. Block diagram of two-level driver circuitry and output wave forms.

(e.g. 120-150 V) according to the TTL pulse, as shown in figure 13. With this new driving topology, we can provide sufficient current required for producing fast rise/fall times (250 $\mu \mathrm{s}$ ) and operating at high frequencies, as opposed to a conventional linear power amplifier ${ }^{1}$. The overall controller implementation can also be represented by a block diagram, as shown in figure 14.

Finally, the switching controller is implemented in Matlab/Simulink and a dSPACE 1102 board with a real-time workshop (RTW) module. The sampling rate is set to be $100 \mu \mathrm{s}$. The dSAPCE system converts analog inputs (i.e. from the pressure transducer) into digital inputs using the built-in A/D converter with 16-bit output resolution. The digital output

\footnotetext{
1 Dynamic Structures \& Materials LLC product catalog.
} 


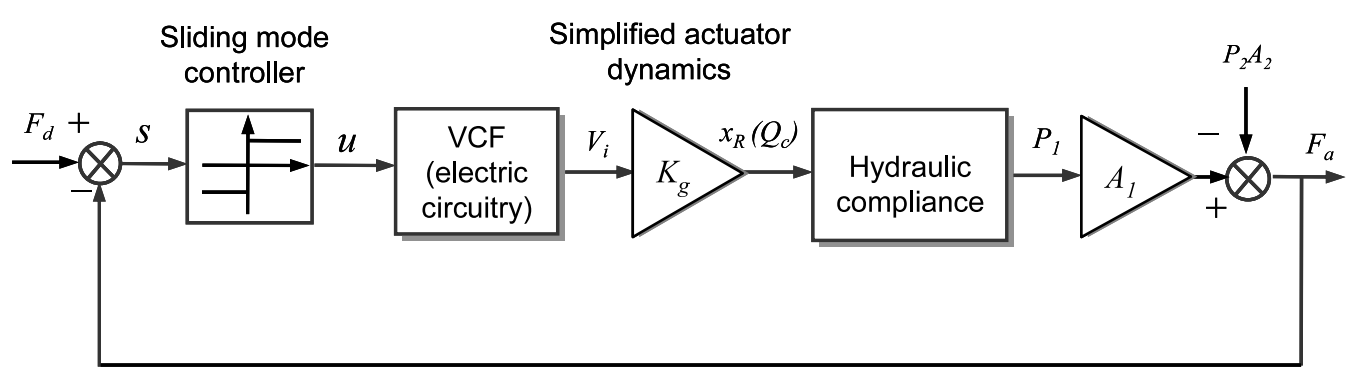

Figure 14. Block diagram for actuation force tracking control.
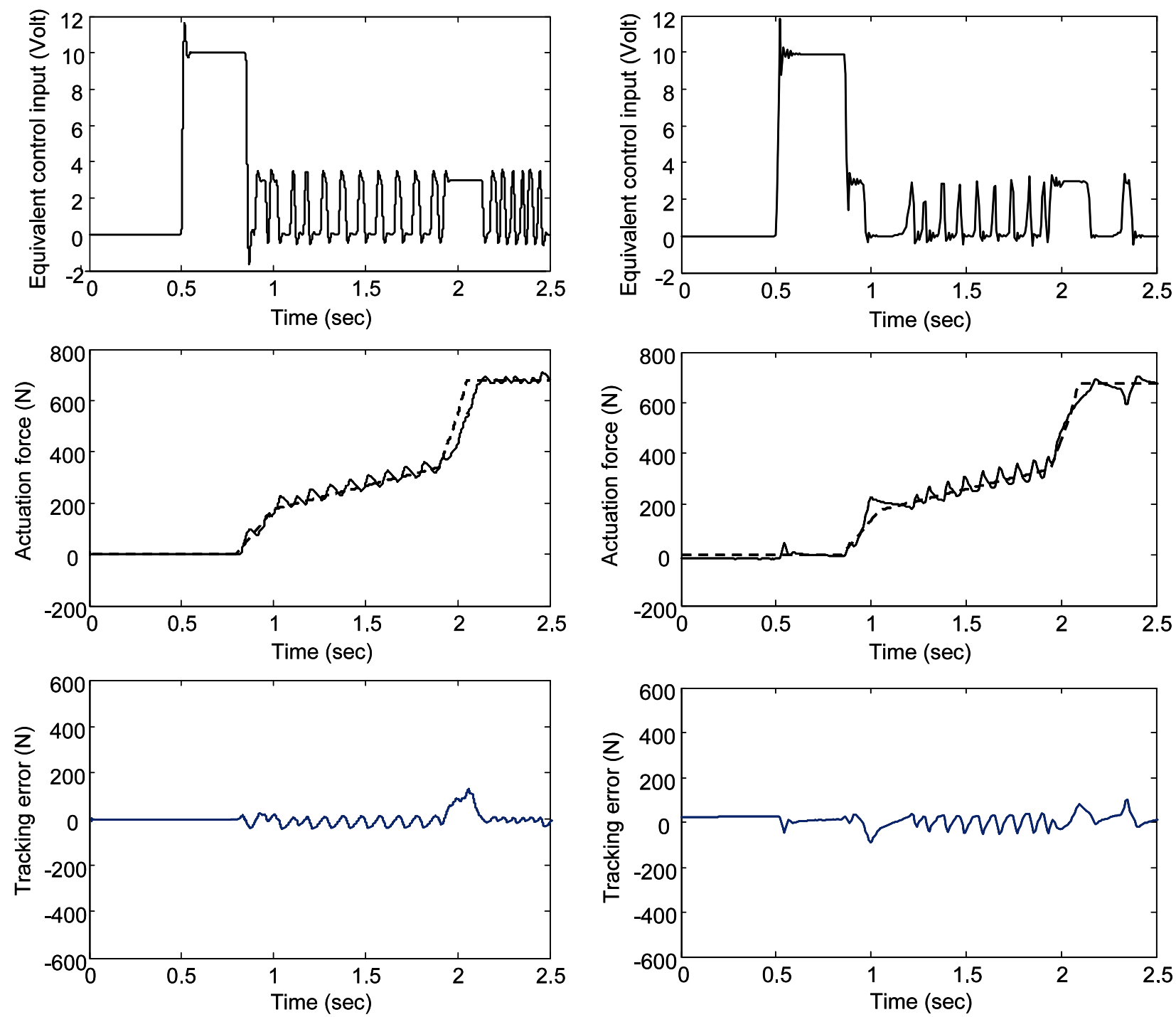

(a)

(b)

Figure 15. Tracking control responses of PHP-based actuation system $\left(P_{2}=0.55 \mathrm{MPa}, V_{\mathrm{i}}=120 \mathrm{~V}, f_{\mathrm{c}}=60 \mathrm{~Hz}\right.$, in the middle graph - - - : reference; — : controlled). (a) Simulation. (b) Experiment.

(i.e. equivalent control input) is converted into an analog output voltage through the built-in D/A converter.

The typical force tracking control responses are illustrated in figure 15. A fill command of $200 \mathrm{~Hz}$ (i.e. $10 \mathrm{~V}$ ) is initially scheduled for $0.35 \mathrm{~s}$. By considering the characteristics of the actuator described in section 2 and the AT shift diagram (figure 2), the desired reference trajectory can be determined. For example, the maximum force $700 \mathrm{~N}$ in the reference trajectory is corresponding to the dead-head pressure of $0.38 \mathrm{MPa}$ under $0.55 \mathrm{MPa}$ accumulator pressure. The control input voltage is $120 \mathrm{~V}$ and the control frequency $f_{\mathrm{c}}$ is set to be $60 \mathrm{~Hz}$ to generate the flow rate satisfying the following 

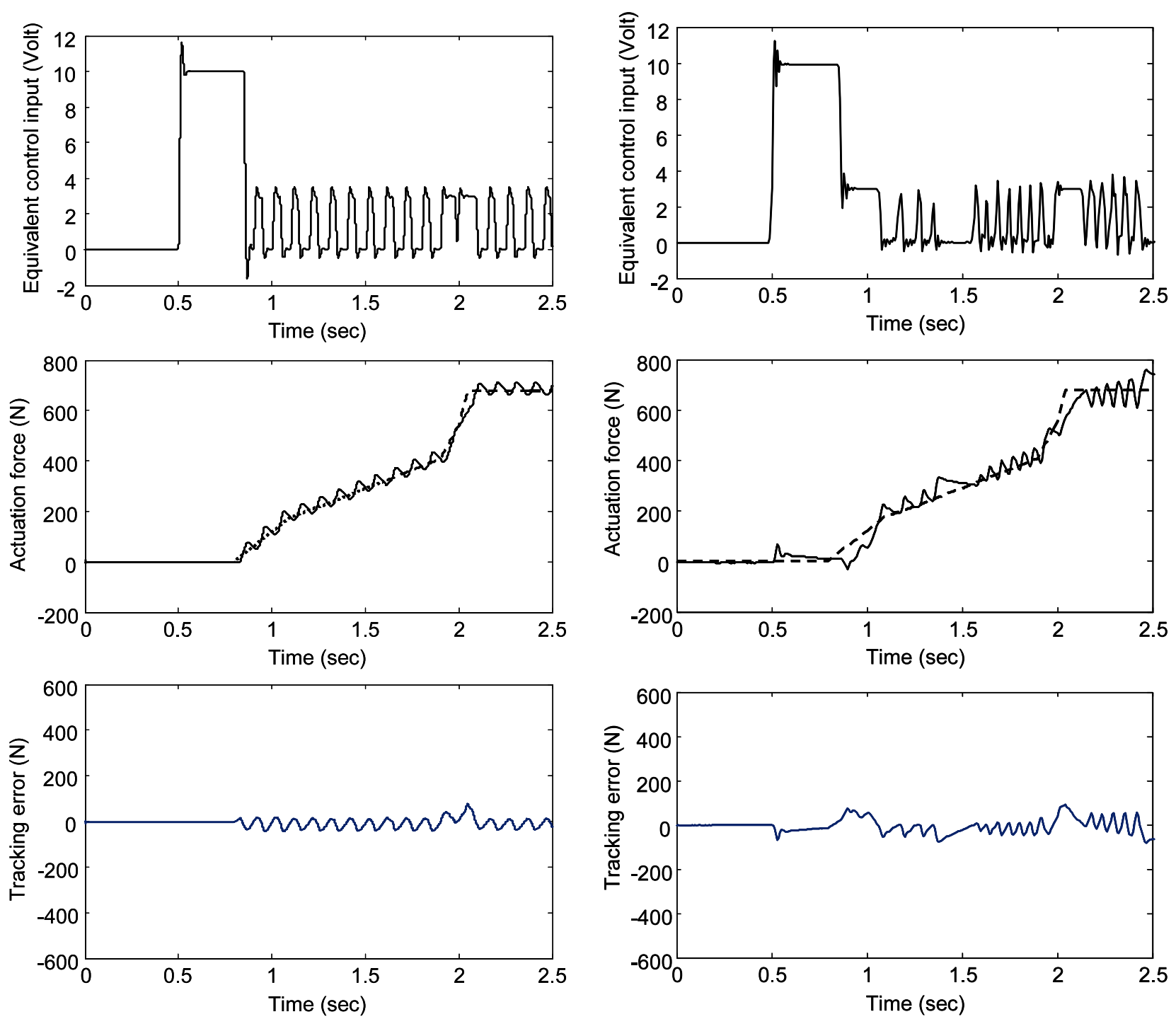

(a)

(b)

Figure 16. Tracking control responses of PHP-based actuation system with different slope trajectory $\left(P_{2}=0.55 \mathrm{MPa}, V_{\mathrm{i}}=120 \mathrm{~V}\right.$, $f_{\mathrm{c}}=60 \mathrm{~Hz}$, in the middle graph - - - -: reference; ——: controlled). (a) Simulation. (b) Experiment.

sliding-mode condition:

$$
Q_{\mathrm{c}}>\frac{1}{\alpha}\left(\eta+A_{1} \alpha \dot{x}+\dot{F}_{\mathrm{d}}\right) .
$$

Under the normal control conditions (accumulator pressure of $\left.0.55 \mathrm{MPa}, \beta_{\mathrm{e}} \approx 150 \mathrm{MPa}\right)$, the required control flow rate $Q_{\text {c }}$ is calculated to be $4 \mathrm{~cm}^{3} \mathrm{~s}^{-1}$ for large $\eta(=10-1000)$, which is generated at a pulse frequency of $40 \mathrm{~Hz}$, as shown in figure 5(a). As illustrated in figure 15, the controlled actuation force can successfully track the desired reference trajectory. Tracking performance for a different trajectory is assessed, as presented in figure 16. While the trajectory is changed, the controller still shows good tracking performance.

Figure 17 shows the effect of lower effective bulk modulus $\left(\beta_{\mathrm{e}} / \beta_{\mathrm{nom}}=0.7\right)$ using lower accumulator pressure $(0.4 \mathrm{MPa})$, which will affect the control flow rate $Q_{\mathrm{c}}$. Due to the lower effective bulk modulus, the hydraulic compliance of the working fluid becomes higher, which in turn causes lower pumping pressure in the control flow rate. It may lead to insufficient control flow rate and lower dead-head pressure. Consequently a slightly under-fill situation occurs at the beginning of tracking control. Saturation also occurs at the end of control due to the insufficient dead-head pressure. However, the controller can still track the desired reference in the inertia phase since the sliding condition is satisfied even though the controlled flow rate has changed. This result indicates that the proposed controller is robust against the variation of the control flow rate.

\section{Conclusions}

In this research, a nonlinear feedback controller based on sliding-mode theory is developed for AT friction element control using PHP-based actuation systems. Analysis and experimental efforts are performed. The results show that the 

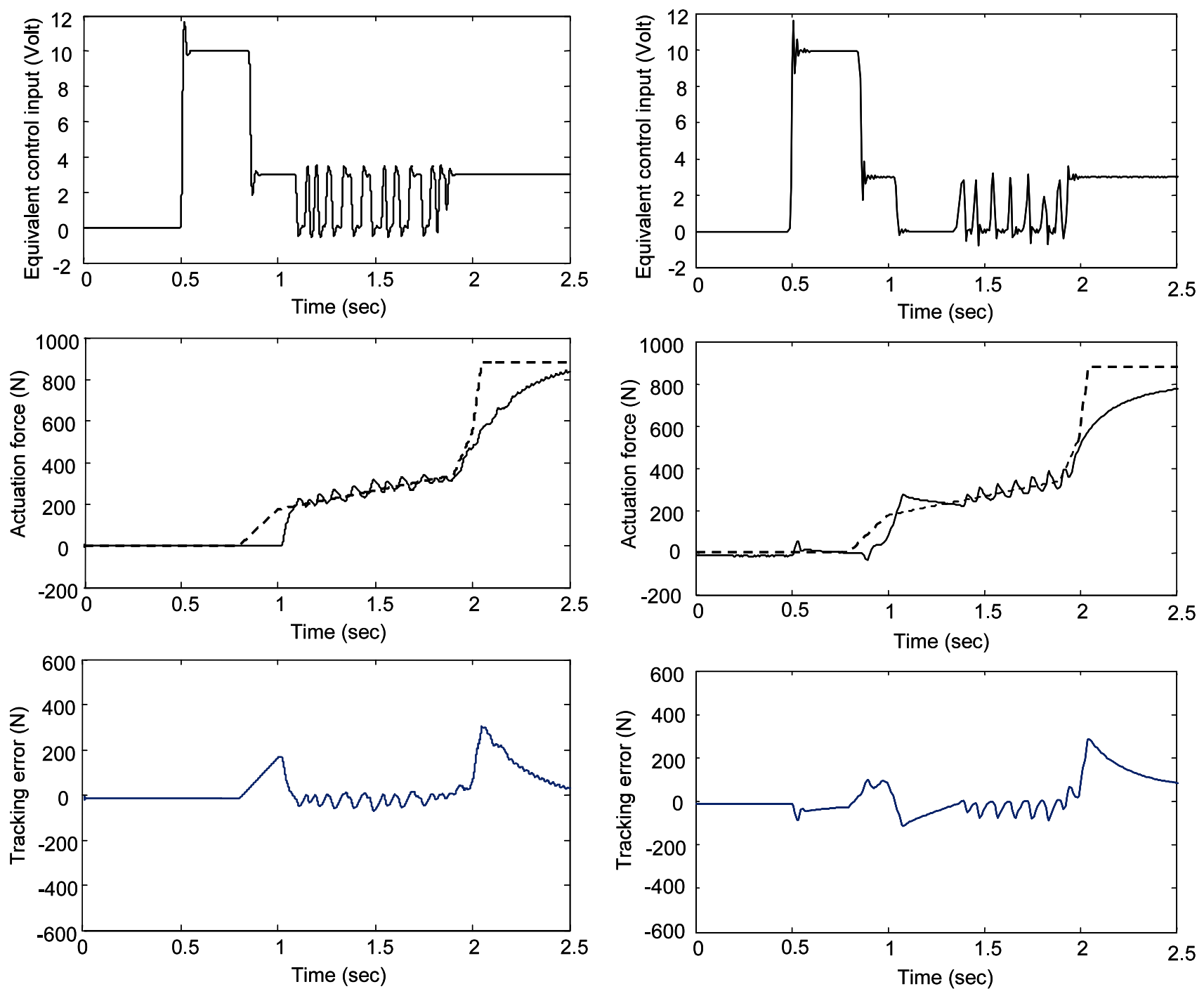

Figure 17. Tracking control responses of PHP-based actuation system with lower dead-head pressure $\left(P_{2}=0.4 \mathrm{MPa}, V_{\mathrm{i}}=120 \mathrm{~V}\right.$, $f_{\mathrm{c}}=60 \mathrm{~Hz}$, in the middle graph - - - -: reference; __ : controlled). (a) Simulation. (b) Experiment.

proposed approach can successfully track the desired actuation force trajectory for AT shift control. This study demonstrates the potential of the PHP-based actuation system and control technology for future automatic transmission systems.

\section{Acknowledgment}

This work is supported by the Ford Motor Company University Research Program.

\section{References}

[1] Deiss H, Krimmel H and Horsak G 2006 Innovative driveline system technology SAE Technical Paper No. 2006-21-0026

[2] Sun Z and Hebbale K 2005 Challenges and opportunities in automotive transmission control American Control Conf. pp 3284-9

[3] Turner A J and Ramsay K 2004 Review and development of electromechanical actuators for improved transmission control and efficiency SAE Technical Paper No. 2004-01-1322
[4] Neelakantan V A, Washington G N and Bucknor N K 2005 Two-stage actuation system using DC motors and piezoelectric actuators for controllable industrial and automotive brakes and clutches Smart Structures and Materials 2005; Proc. SPIE 5762 275-86

[5] Turner A J, Ramsay K, Clark R E and Howe D 2006

Development of high force electromechanical linear actuator for shift-by-wire automated manual transmissions $S A E$ Technical Paper No. 2006-01-0360

[6] Nasser K, Leo D J and Cundey H H 2000 Compact piezohydraulic actuation system Smart Structures and Materials 2000; Proc. SPIE 3991 312-22

[7] Oates W S and Lynch C S 2001 Piezoelectric hydraulic pump system dynamic model J. Intell. Mater. Syst. Struct. $12737-44$

[8] Sirohi J and Chopra I 2003 Design and development of a high pumping frequency piezoelectric-hydraulic hybrid actuator J. Intell. Mater. Syst. Struct. 14 135-47

[9] Tan H, Hurst W and Leo D J 2005 Performance modeling of a piezohydraulic actuation system with active valves Smart Mater. Struct. 14 91-110

[10] Kim G W and Wang K W 2007 Piezoelectric-hydraulic pump based brake actuation system for automotive transmission control Smart Structures and Materials; Proc. SPIE $\mathbf{6 5 2 5} 65251 \mathrm{E}$ 
[11] Kim G W and Wang K W 2008 Nonlinear force feedback control of piezoelectric-hydraulic pump actuator for automatic transmission shift control Smart Structures and Materials 2008; Proc. SPIE 6930 69300A

[12] Fujii Y, Tobler W E, Clausing E M, Megli T W and Haghgooie M 2002 Application of dynamic band brake model for enhanced drivetrain simulation Inst. Mech. Eng. D $216873-81$

[13] Yury K and Naeim A H 2007 Stress analysis of multilayer piezoelectric actuators for diesel fuel injection subjected to square pulse voltage excitation Smart Structures and Materials 2007; Proc. SPIE 6527 65270T

[14] William R D and Stanley I G 1982 Elementary Differential Equations with Applications (Reading, MA: Addison-Wesley)

[15] Slotine J E and Li W 1991 Applied Nonlinear Control (Englewood Cliffs, NJ: Prentice-Hall)

[16] Watton J 1989 Fluid Power Systems (Englewood Cliffs, NJ: Prentice-Hall) 